\title{
The Training of Divisional Reading Room Librarians
}

Dr. Ellsworth's article makes it evident that the divisional plan for college and university libraries implies changes in staffing and in the preparation of those who are to do the work of the divisions.

$\mathrm{T}$

HE CURRENT trend toward planning university and college libraries around some subject or combination of subjects as at Brown, Colorado, Nebraska, and elsewhere, instead of around traditional library functions such as reference, reserve, circulation, and periodicals, naturally brings up the question of how librarians can prepare themselves for this new type of work. Library schools, as everybody knows, have in general based their curricula on the assumption that their graduates will work according to library functions. Thus, we have had courses in acquisition, reference, cataloging and classification, government documents, etc.

But if function is to be subordinated to subject or if divisional librarians are to perform all the traditional library functions in relation to a subject area, then perhaps the library schools will need to adjust their curricula accordingly, at least in the college and university library fields. The implications of the question would seem to deserve discussion at this time.

Such discussion must begin with careful definitions of what is meant by divisional libraries and of the possible jobs that divisional librarians might undertake. The variations among existing divisional read- ing room plans and contemplated plans are considerable. These variations appear to group themselves around three distinct types of service.

\section{Imposed Divisions}

Under this plan the library keeps intact its traditional room functions, such as reference, reserve, periodicals, and closed stack circulation, but adds subject service through departmental libraries and by establishing special subject reading rooms for more specific purposes. The reading rooms usually contain a small collection of books for course work. No attempt is made to merge all the publications pertaining to the field. The librarian of such a room is concerned primarily with records and physical problems, that is, he works with instructors to see that the right books are in the collection. He tries to keep the collection in order and to circulate books for overnight use. There is usually a minimum amount of reference work connected with this type of service because it is tied up primarily with making books available for courses. In the early stages, at least, the work is not unlike that of a reserve librarian and does not offer an opportunity for use of more knowledge of the subject concerned. For this work there is little opportunity for library schools to develop a type of training that would be significantly better than what we now have.

\section{Intermediate Division}

A second step is the establishment of sub- 
ject divisional rooms which absorb most of the standard functions, such as reserve, periodicals, some parts of reference, document, and stack circulation. Here the divisional or area librarian attempts to manage all library functions for one or more subject fields. $\mathrm{He}$ is reference librarian, reserve librarian, periodicals librarian for one or more fields. He may find it necessary to confine most of his time to the mechanics of this work; or, if he can routinize these, he has an unlimited opportunity to devote his time to the reading problems of a subject field as well as to the more interesting bibliographic problems. The concentration of function immediately brings him into close contact with the instructor and the student, and he must know a good deal about the subject area itself. The more he knows the more he can develop the reference side of his work. A librarian in charge of this kind of room who has only the standard A.B. and B.S. in L.S. is in the embarrassing position of not knowing enough about the subject field in his area to extend the range of his control with advanced students and faculty members. If he holds an M.A. or a $\mathrm{Ph} . \mathrm{D}$. in a subject field, he knows enough in one or two fields to go ahead but his knowledge is usually limited to parts of the area he works with. Furthermore, he finds himself dealing with the technical processes divisions of the library organized on the traditional basis.

A librarian trying to administer this type of organization begins to ask himself how he can merge all library processes on the divisional basis, and he faces questions he cannot answer. For example, why not split the cataloging and classification departments among the divisions? Why not circulate all books in the stacks through the division? Why not break up the main cata$\log$ into the division? Why not decentralize the order department so that much of the ordering can originate from the reading rooms, where needs are first realized? The possibilities are interesting, but the practical obstacles to be overcome are considerable.

My experience with the library at this stage of development at the University of Colorado suggests that the divisional librarian must have the following minimum qualifications: namely, a well-rounded general education at the bachelor of arts level, the standard one-year library course, and at least a master's degree in one of the subject fields involved. A Ph.D. would be far better, but present library salary scales make this impracticable. Library training alone is insufficient, and subject training alone does not work too well. Much of the library school training is wasted in such positions, as is some of the training received in graduate school. A more logical preparation would seem to be a two-year curriculum developed in a library school where the candidate is given a very concentrated dose of technical training, six weeks at the most, and where the rest of the time would be spent in analyzing the bibliographic apparatus, the structure of the literature, and the working problems of scholars and learners in a subject area.

Where the divisional librarian is well enough educated and where he is acceptable, the idea of having him teach a course in a subject field is helpful. A unit of teaching for which the divisional librarian might be responsible is a course in bibliographic methods for graduate students. We librarians must recognize that the bibliographic training we receive in the first-year library school is not sufficient background for this course. To this work it is necessary to add courses in methods of research.

The special training of lower divisional librarians or general college librarians presents an interesting problem, but discussion of it will come later in this paper. 


\section{Instructional Division}

The conception of a divisional library, as treated above, takes the librarian far astray from traditional procedures, but it stops short of complete fusion of the subject instruction and library activities. The third type, which is being approached at Colorado and which is being sought vigorously at the State University of Iowa in its new building program, merely follows the second plan to its logical conclusion; that is to say, it merges the function of the library and the instructional program of the university and merges the function of the librarian and that of the teacher. Lest the discussion dissolve itself into jargon, the following outline of how such a program would look and work is presented.

For the educational function which might be called "general education" or "lower division" or "core" or "college," a reading area which included reading room space, classrooms, consultation rooms, phonograph record listening rooms, faculty office rooms, and faculty research rooms might be built around a civilization arrangement. The following concentrations would be logical: early Oriental civilization, Greek and Roman, Christian and medieval, Renaissance, Industrial Revolution, age of nationalism, and contemporary.

For each concentration one would place multiple copies of the titles of books that represent the ideas that were significant in the period, examples of the art and music, models of homes, buildings, transportation systems, agricultural organizations, business organizations, etc., arranged according to the best museum treatment. The purpose is to reconstruct, insofar as this is possible, the essential contributions of each civilization in a manner that will challenge the imagination of young learners. Thus a student would be able to see the development of man's culture in rela- tion to time sequence. The number of book titles needed for this job would not be extensive, but they would certainly be greater than the one hundred best books. The reason for using many nonprint materials in such concentrations is obviously to try to offer the student a presentation that will serve as a study guide to the library.

The curriculum in the lower division area which would be used with this type of library might be based on an analysis of civilization or it might be based on traditional subjects. The library would serve best with the first type of curriculum but would work satisfactorily with the second. The advantages would be, of course, that the student would be able to understand what was known about each field of knowledge at a particular time. Presumably this would be a help to him in understanding his heritage.

Such a library requires a considerable amount of space. It should be so planned that much of the instruction could be done in the library, both with groups and individual units. It would include all subjects as they entered man's cultural development.

The librarian in charge would not have many technical duties to perform outside of presentation. He would have a part in the directing of the curriculum and in the teaching process itself.

The reading room areas to be provided for advanced students and faculty in the nonlaboratory departments could, by providing space for recognized functions, go far in coordinating library and instructional programs. The functions which must be combined are: small and intimate reading room areas surrounded by relevant books, pictures, and records; faculty research quarters and faculty consultation rooms; classrooms or seminars; rooms for special laboratory functions such as statistical machines; record playing rooms; microfilm equipment; map rooms; group 
meeting rooms; rooms equipped for moving pictures, slides, housing for objects, and lounging areas; and phonetics laboratories.

In other words, for the humanities and social studies the divisional reading rooms can be the place where most of the activities of students and faculty members take place. It is clear that the administration of these functions around a subject area calls for an exercise of librarianship that is different from what has been considered the province of the profession. Certainly there will be technical work to be done, and the librarians will have to do it. But who will direct the program, a librarian, or a teacher, or someone who is both?

The answer to that question will be determined, in my judgment, not on theoretical bases, but in terms of the kind of librarians available when such positions open up. If there are librarians who are obviously capable of doing this work, then they will be hired. Otherwise, professors will be placed in charge. In this respect the problem is comparable to that faced by large universities in the last ten years in the employing of directors of libraries. Wherever capable librarians have been available, they have been hired. Where they have not been available, professors have been put in charge.

If this is true, then the library schools have an opportunity to begin now preparing a few hand-picked students for this type of work. No one likes to be a guinea pig, but in this case the student would be taking little risk, because there are many librarians today who would jump at the opportunity of hiring staff members trained in this manner.

\section{Suggestions for a Curriculum}

The faculties of the library schools are perhaps in the best position to determine how such a curriculum should be developed, but a few suggestions by a layman might be in order.

I. In the realm of technical processes, little time need be devoted to nonbibliographic problems, except that possibly some work should be concentrated on cataloging apparatus as a tool device. Outside of the technical processes work the student should spend most of his time studying the bibliographic apparatus of subject fields, the working procedures of scholars, and the reading problems of students at all levels. By this I do not mean graduate work for an advanced degree in a subject area. That may be valuable, but it does not provide the breadth of training or the knowledge of bibliographic apparatus that is needed for the type of work under discussion. Some of the courses on methods of research given by subject departments will be a satisfactory way of introducing a student to a subject area, but these would have to be carefully scrutinized by the faculty concerned with developing a particular student's program. To some extent the approach employed at the Graduate Library School of the University of Chicago is a satisfactory one for this purpose.

2. The student will want to spend a certain amount of time studying the development of institutions of higher learning in this country and abroad and the philosophic considerations that are determining the future development of colleges and universities.

3. The student might well be acquainted with some of the actual problems a librarian faces in terms of how a university works, through its administrative machinery, its committee functions, its social structure, its "beer garden" approach to problems, and its departmental alignments and politics. These are matters that are not written into administration textbooks but they are ad-

(Continued on page 19) 
tions $^{8}$ listed as essential to the positions they hold, there remained the difficult task of writing job specifications for each library position. It will be remembered that one of the primary reasons for undertaking the whole program of self-survey was to explain to the college administration how the work of each person on the staff contributes to the educational program of the entire institution. To describe library positions, keeping such a purpose in the foreground, doing it in nontechnical terms, and making the descriptions reasonably short and at the same time explicit, is no simple undertaking. The examples given in the A.L.A. plans ${ }^{9}$ were thought to be too gen-

8 Ibid., p. I 5.I I I

Ibid., p. 15-101. eral in character to be intelligible to a nonlibrarian. However, they were used as models for considerably more specific accounts of each job.

Finally, the entire survey was described fully in the form of a report to the board of trustees. Conclusions emphasize the fact that an entirely new method of measuring the library shows results in complete agreement with other studies submitted within the last five years. The inevitable recommendation is a considerably increased budget for books and salaries, without which further development of library service to the college will be limited to what the staff can achieve on present resources of time and money.

\section{The Training of Divisional Reading Room Librarians}

\section{(Continued from page 7)}

ministrative realities, as anyone very closely associated with universities can testify.

If it is to be assumed that the divisional librarian is to have some definite instructional function, then obviously he or she must be able to teach. To be a professor one must profess. This may take several forms : first, straight classroom teaching in a subject; second, teaching the bibliographic apparatus techniques for a special field; third, a semitutorial arrangement worked out to fit in with the needs of the faculty in a department. Common to all, though, is the fact that the librarian must know a good deal about at least one subject area, regardless of what else he knows.

\section{Summary}

The essence of this discussion is that the pattern of divisional library service is not yet set. Library schools have a great opportunity for leadership by striking out into new curricula that will provide librarians capable of establishing a pattern of service for divisional librarians. 